Andreu, C.R y Riccobene, E. Aproximación a un enfoque entre la globalización capitalista y la cuestión de la gobernanza. Derecho y Ciencias Sociales. Abril 2017. $\mathrm{N}^{\circ} 16$ (Temas relativos al desarrollo regional y local) Pgs 56-72. ISNN 1852-2971. Instituto de Cultura Jurídica y Maestría en Sociología Jurídica. FCJ y S. UNLP.

\title{
Aproximación a un enfoque entre la globalización capitalista y la cuestión de la gobernanza.
}

Capitalist globalization on state governance.

\author{
Ricardo C.Andreu \\ Eliseo Riccobene $\bullet$
}

\section{Resumen.}

El debate sobre la globalización se ha ido centrando crecientemente sobre la relación del estado-nación con globalización económica. Pero el problema de la globalización y del estado ha sido parcialmente enfocado. O el estado-nación (y el sistema intra-estatal) es visto como el eje de las relaciones internacionales y del desarrollo mundial en una construcción dualista que plantea una lógica separada para una globalización económica y para un sistema político basado en un estado-nación, o el estado es visto, como ocurre en muchas tesis sobre "el fin del estado-nación", como si ya no fuera realmente importante.

Con el fin de clarificar las relaciones entre la globalización y el estado-nación, desde una perspectiva crítica más allá de este dualismo global-nacional se incorpora el concepto del estado transnacional (ETN).

Para explorar sobre estas bases se propone analizar tres ejes: 1) la globalización económica tiene su contrapartida en la formación transnacional de clases y en la emergencia de un estado transnacional (en adelante ETN) que ha venido a existir para funcionar como la autoridad colectiva para la clase global gobernante; 2) el estado nacional no retiene su primacía ni ha desaparecido sino que se ha ido transformando y ha sido absorbido en esta estructura más amplia del ETN; 3) este ETN emergente institucionaliza una nueva relación de clases entre el capital global y el trabajo global.

Palabras Clave: globalización, capitalismo, estado, gobernanza, crisis.

\begin{abstract}
.
The debate on globalization has been increasingly focused on the relationship of the nation-state with economic globalization. But the problem of globalization and the state has been partially focused. Some consider the nation-state (and the intra-state system) is seen as the center of international relations and world development in a dualist construction that raises a separate logic for an economic globalization and for a nation-state-based political system; Others affirms, as it happens in many theses on "the end of the nation-state", it is not really important anymore.

In order to clarify the relations between globalization and the nation-state, from a critical perspective beyond this global-national dualism, the concept of the transnational state (TNS) is incorporated.

To explore on this basis it is proposed to analyze three axes: 1) economic globalization has its counterpart in the transnational formation of classes and in the emergence of a transnational state (hereinafter TNS) that has come to exist to function as the collective authority for The ruling global class; 2) the national state does not retain its primacy nor has it disappeared but has been transformed and absorbed into this broader structure of the TNS; 3 ) this emerging TNS institutionalizes a new class relationship between global capital and global labor.
\end{abstract}

Key words: globalization, capitalism, estate, governance, crisis.

- Ricardo César Andreu. Lic en Economìia (UBA). Prof Adjunto de Economía política. Docente Investigador Programa incentivos- UNLP.

• Eliseo Riccobene. Abogado por la FCJyS de la UNLP; Auxiliar Docente de la Cátedra II de Economía Política de la FCJyS UNLP; alumno de la Especialización en Derecho Empresario de la FCJS de la UNLP; Becario de Investigación y Perfeccionamiento UNLP. Contacto: eliseo640@yahoo.com.ar 
Andreu, C.R y Riccobene, E. Aproximación a un enfoque entre la globalización capitalista y la cuestión de la gobernanza. Derecho y Ciencias Sociales. Abril 2017. № 16 (Temas relativos al desarrollo regional y local) Pgs 56-72. ISNN 1852-2971. Instituto de Cultura Jurídica y Maestría en Sociología Jurídica. FCJ y S. UNLP.

Aproximación a un enfoque entre la globalización capitalista y la cuestión de la gobernanza.

Ricardo C. Andreu

Eliseo Riccobene

\section{La Gobernabilidad y la Gobernanza (desarrollo conceptual).}

Es preciso - y desde un punto de vista metodológico resulta incluso constitutivo del orden expositivo -, delimitar conceptualmente los términos a partir de los cuales estructuraremos el presente trabajo.

Dicha tarea la elaboraremos a partir del análisis previo sobre el concepto de Gobernanza y Gobernabilidad realizado por diversos autores.

En este sentido, Antonio Camou defina a la gobernabilidad como:

"Un estado de equilibrio dinámico entre el nivel de las demandas societales y la capacidad del sistema político (estado/gobierno) para responderlas de manera legítima y eficaz" (Camou, 2001).

Ello supone una definición amplia del término, que encierra un gran número de variables que lo componen, las cuales se vinculan entre sí de manera justamente "dinámica” para lograr un equilibrio.

Así para él, la gobernabilidad debe involucrar en la definición una "serie de 'acuerdos' básicos entre las élites dirigentes (...) en torno a tres ámbitos principales (...) el nivel de la cultura política (...) el nivel de las reglas e instituciones del juego político (...y) acuerdos en torno al papel del Estado y sus políticas públicas estratégicas” (Óp. Cit.).

Esta perspectiva, apunta a analizar la puja del poder por parte de los diferentes grupos políticos que lo detentan a nivel intra-estatal, y cómo logran consensuar sus aspiraciones de manera que puedan alcanzar ese punto de equilibrio necesario.

Asimismo, Camou distingue entre gobernabilidad (governability) y gobernanza (governance), haciendo mención que el primer concepto indaga "cómo" se gobierna, cristalizando una categoría que hace al mecanismo dinámico interno del funcionamiento institucional nacional y cómo a través del mismo se conjugan dos propósitos: la estabilidad política y el aseguramiento de los derechos de los ciudadanos.

Por otro lado, se refiere a la gobernanza como "la manera específica en que los gobiernos establecen sus agendas, diseñan sus políticas, toman sus decisiones y evalúan sus impactos" 
Andreu, C.R y Riccobene, E. Aproximación a un enfoque entre la globalización capitalista y la cuestión de la gobernanza. Derecho y Ciencias Sociales. Abril 2017. № 16 (Temas relativos al desarrollo regional y local) Pgs 56-72. ISNN 1852-2971. Instituto de Cultura Jurídica y Maestría en Sociología Jurídica. FCJ y S. UNLP.

(Óp. Cit.:20). Esta última idea, engloba una visión totalizadora del contexto político mundial, y cómo se insertan los países en dicho escenario internacional.

Este autor concluye vinculando los temas de gobernanza y gobernabilidad, argumentando que puede existir una articulación adecuada en el caso de darse "una serie de acuerdos básicos entre las élites dirigentes y una mayoría significativa de la población” (Op. Cit.:51) que adoptan un carácter institucional, reduciendo la incertidumbre y proporcionando legitimidad a las acciones de gobierno.

La legitimidad es una cualidad de la gobernabilidad; la estabilidad tiene que ver con el estado de la gobernabilidad, y la eficacia/eficiencia es una propiedad de la gobernabilidad.

Así, cuando se aborda la relación entre gobernabilidad y eficacia, "la gobernabilidad es pensada como una propiedad de los sistemas políticos definida por su capacidad para alcanzar objetivos prefijados al menor costo posible” (Op. Cit.:33). Cuando se trata de la relación entre gobernabilidad y legitimidad la atención se refiere "al problema de la calidad de la acción gubernamental”. Y cuando la relación se establece entre estabilidad y gobernabilidad se apunta a "la previsible capacidad del sistema de durar en el tiempo" puesto que un sistema es estable cuando tiene capacidad para transformarse a través de su adaptación a los desafíos que provienen de su entorno" (Op. Cit: 35).

En otras palabras, los sistemas políticos adoptan determinado modelo de gobernabilidad de acuerdo con las exigencias de un entorno cambiante, lo que los hace netamente dependientes a uno del otro, más allá de sus diferencias teóricas conceptuales.

Por otro lado, Joan Prats define la gobernabilidad como "un atributo de las sociedades que se han estructurado sociopolíticamente de modo tal que todos los actores estratégicos se interrelacionan para tomar decisiones de autoridad y resolver sus conflictos conforme a un sistema de reglas y de procedimientos formales e informales (...) dentro del cual formulan sus expectativas y estrategias" (en IIG 2003:28).

Es decir, la gobernabilidad es postulada como una cualidad de las sociedades o sistemas sociales, "no de sus gobiernos" (Prats 2001:120)

Michel Coppedge (en Camou 2001), define la gobernabilidad como "el grado en el cual el sistema político se institucionaliza" y la institucionalización, como "el proceso por el cual las organizaciones y los procedimientos adquieren valor y estabilidad". Identificando como actores estratégicos típicos en América Latina al gobierno, el ejército, la burocracia y las empresas estatales (Estado), las asociaciones empresariales los sindicatos de trabajadores, 
Andreu, C.R y Riccobene, E. Aproximación a un enfoque entre la globalización capitalista y la cuestión de la gobernanza. Derecho y Ciencias Sociales. Abril 2017. $\mathrm{N}^{\circ} 16$ (Temas relativos al desarrollo regional y local) Pgs 56-72. ISNN 1852-2971. Instituto de Cultura Jurídica y Maestría en Sociología Jurídica. FCJ y S. UNLP.

organizaciones campesinas, la Iglesia y otros grupos de interés (sociedad) y los partidos políticos.

Por ello para Prats, la gobernabilidad implica así la conformación de una matriz institucional que expresa la estabilidad o equilibrio del sistema sociopolítico y que cuando es incapaz de procesar el conflicto entre actores ingresa en una situación de crisis que exige no solamente una modificación de reglas o procedimientos sino de la propia matriz institucional, (en IIG 2003:28).

Finalmente, Fernando Calderón (en Camou 2001), considera que la noción de gobernabilidad está referida "a la capacidad política de una sociedad y debe ser vista como una construcción de la política"; la gobernabilidad democrática, por su parte, se refiere "a la construcción de un orden institucional plural, conflictivo y abierto" que implique "una capacidad mínima de gestión eficaz y eficiente y de autoridad que tendría que tener el poder ejecutivo frente a los otros poderes y la sociedad misma" (Op. Cit.:263), y propone una relación entre gobernabilidad, competitividad e integración social, es decir, entre estado, mercado y sociedad civil (este concepto fue trabajado por B. de Sousa Santos en Sociología Jurídica Crítica cap. 6), rescatando también la noción de actores estratégicos en conflicto, con la diferencia de que "el conflicto (...) supone una disputa entre los distintos actores por la dirección cultural de la gobernabilidad, la competitividad y la integración social" (Op. Cit.:274), "que se refuerzan entre ellos e interactúan sinérgicamente en sentido positivo o negativo" (Op. Cit.:271).

Así también para Prats, al momento de estudiar el aspecto metodológico del concepto de gobernabilidad, hay que tener en cuenta que "todo análisis de gobernabilidad comienza identificando en un momento histórico dado los actores estratégicos -internos e internacionales - , los recursos de poder que controlan, su solidez interna, sus expectativas, sus mapas mentales, su capacidad para representar o para agregar los intereses que dicen representar o expresar, el tipo de alianzas estratégicas -internas o internacionales - y los conflictos en lo que están envueltos" (en IIG 2003:29).

También Coppedge (en Camou 2001) parte de la premisa de que mientras menor es el nivel de abstracción resulta más útil la información para estudiar la gobernabilidad,

Camou distingue dos tipos de niveles de análisis: uno referido a los niveles jurisdiccionales (o reales) de gobierno, y otro referido a los niveles analíticos de gobernabilidad.

En el primer tipo se contempla los ámbitos característicos del ejercicio gubernamental (nacional, regional y local); asimismo, diferentes sectores sociales o esferas de acción 
Andreu, C.R y Riccobene, E. Aproximación a un enfoque entre la globalización capitalista y la cuestión de la gobernanza. Derecho y Ciencias Sociales. Abril 2017. № 16 (Temas relativos al desarrollo regional y local) Pgs 56-72. ISNN 1852-2971. Instituto de Cultura Jurídica y Maestría en Sociología Jurídica. FCJ y S. UNLP.

(economía, sector industrial, educación superior), diversos actores estratégicos (empresarios, trabajadores, Fuerzas Armadas), alguna organización compleja (una universidad pública) y, finalmente, la dimensión supranacional de la gobernabilidad, sea regional o global (Op. Cit.2001:23)

El segundo tipo se refiere a los niveles analíticos de gobernabilidad y comprende de manera genérica el sistema económico (mercado), el sistema político administrativo (incluido el Estado) y el sistema sociocultural (sociedad civil). Esta precisión analítica permitiría situar los problemas de gobernabilidad, ya sea en el nivel general del sistema político y sus relaciones con el mercado y la sociedad civil, o, en todo caso, en algunos de los componentes del sistema político, particularmente el Estado y el gobierno, e inclusive de manera más específica en el poder ejecutivo.

Calderón (en Camou 2001), al definir el término, se acerca a esta delimitación: "la noción de gobernabilidad está asociada a una capacidad mínima de gestión eficaz y eficiente y de autoridad que tendría que tener el poder ejecutivo frente a los otros poderes del Estado y a la sociedad misma" (Op. Cit.:265).

El concepto de Gobernanza, pasó de referirse meramente a la acción del gobierno o ejercicio del gobierno en una región (Loyo 2002:2) al "marco de reglas, instituciones y prácticas establecidas que sientan los límites y los incentivos para el comportamiento de los individuos, las organizaciones y las empresas" (Elena Martínez, Directora del Buró de América Latina y el Caribe del PNUD, en Prats 2001:119).

No existe en la producción bibliográfica latinoamericana un texto que sintetice y sistematice el uso de este concepto y por ello las definiciones varían relativamente en función de los estudios de caso, tan variados en su enfoque como en los temas abordados.

Así, se analiza la gobernanza en relación con las políticas públicas en salud y la participación ciudadana (Zeledón y Orellana 2003), los recursos hídricos en la región andina (Programa Minga, IDRC 2003); asimismo, la gobernanza ambiental en comunidades campesinas afectadas por la explotación minera (Decoster 2003), la gobernanza urbana (Stren 2000), la gobernanza local y la lucha contra la pobreza (Román y Retolaza 2001), hasta, inclusive, la posibilidad de entender la gobernanza como integración regional bajo pautas de gobernabilidad (Cimadamore 2004).

Campero la considera "como la capacidad técnica del Estado para responder a las demandas sociales y económicas con eficiencia y transparencia” (Campero 2002:2). 
Andreu, C.R y Riccobene, E. Aproximación a un enfoque entre la globalización capitalista y la cuestión de la gobernanza. Derecho y Ciencias Sociales. Abril 2017. № 16 (Temas relativos al desarrollo regional y local) Pgs 56-72. ISNN 1852-2971. Instituto de Cultura Jurídica y Maestría en Sociología Jurídica. FCJ y S. UNLP.

Balbis (2001), por su parte expresa la necesidad de considerar que "el Estado no es el único ni el principal actor del desarrollo (...) a su lado se halla el mercado (representado por la empresa, instituciones e individuos, consumidores y productores) y se realza el papel de la llamada sociedad civil (...) que engloba a las ONG, las cooperativas, las mutualidades, los sindicatos y las organizaciones de base comunitaria, las fundaciones, los clubes sociales y deportivos, etc." (Op. Cit.:7).

A diferencia de la reflexión en torno al concepto de gobernabilidad, ampliamente trabajado en la región, no existe un esfuerzo similar acerca de la gobernanza.

Como dijimos, el concepto de Gobernanza en la región, no ha sido trabajado con la misma amplitud que la definición de Gobernabilidad, y la mayoría de los trabajos se basan en las definiciones del PNUD y del Banco Mundial porque están referidas solo a la implementación e impacto de políticas públicas.

\section{La emergencia del Estado Transnacional (La configuración de la gobernanza a nivel}

\section{global)}

Luego de haber delimitado los conceptos de Gobernabilidad y Gobernanza vamos a introducir dos enfoques sobre los cambios producidos por el proceso de globalización y las persistentes dificultades que se producen en el curso de la Crisis Internacional. Confrontaremos dos hipótesis disímiles en cuanto a contenido de los conceptos nombrados anteriormente Uno de los enfoques se basa en una visión que reivindica la construcción clásica de la Democracia (la heredada de la Ilustración) (Susan George 2014).

En el primer enfoque que dada su propia definición lo podemos caracterizar como partidario de las ideas de la ilustración, la hipótesis se fundamenta en que la autoridad ilegítima va en aumento y que la democracia está sucumbiendo poco a poco a la enfermedad de la ideología neoliberal. Progresivamente más funciones de los gobiernos legítimos están siendo asumidas por organizaciones ilegítimas, no electas, de agentes no transparentes, tanto en los niveles, nacional, regional e internacional.

Lo ilegítimo y lo antidemocrático es identificado como "gobernanza".

Se refiere al poder de las corporaciones más grandes y de acuerdo a la formulación de las Naciones Unidas de "transnacional" o se adopta el nombre "Empresa Multinacional" (EM).

La verificación de legitimidad son la existencia de elecciones libres y justas, el gobierno constitucional, el Estado de Derecho, la igualdad ante la ley; separación de los poderes ejecutivo, legislativo y judicial, controles y equilibrios para evitar que cualquier parte del 
Andreu, C.R y Riccobene, E. Aproximación a un enfoque entre la globalización capitalista y la cuestión de la gobernanza. Derecho y Ciencias Sociales. Abril 2017. $\mathrm{N}^{\circ} 16$ (Temas relativos al desarrollo regional y local) Pgs 56-72. ISNN 1852-2971. Instituto de Cultura Jurídica y Maestría en Sociología Jurídica. FCJ y S. UNLP.

gobierno no se vuelva demasiado poderoso, la separación de Iglesia y Estado. A lo que se agrega los derechos y libertades individuales y colectivas como establece la Declaración Francesa de los Derechos del Hombre y del Ciudadano de 1789 y la Declaración de Derechos de 1791 compuesta por la primera diez enmiendas a la Constitución de los Estados Unidos de América.

En oposición el neoliberalismo a pesar de haber sido completamente desacreditado intelectual, práctica y moralmente ha triunfado y sigue causando enormes cambios de poder en favor de las clases y las corporaciones más ricas y poderosas.

Esto se manifiesta entra otras cuestiones en la evolución de la repartición en la distribución del producto Los asalariados han perdido diez puntos del PIB, en relación a la década del 1970, cambio que no es pequeño. El PIB de Europa es unos \$ 13 billones de dólares por año, por lo que los trabajadores europeos están perdiendo unos \$ 1.300 millones de dólares (\$ 1.300.000.000.000) al año en comparación con la década de 1970. Cuando los trabajadores perciben sus ingresos estos se dirigen mayoritariamente a la compra de bienes y servicios-que mantiene la economía en funcionamiento.

Para el decálogo neoliberal, las acciones del Estado de bienestar son vistas como expoliaciones de los recursos de los Ricos, que supuestamente crearon la riqueza, y dando esa riqueza a los que no lo merecen. En su visión Los ricos no les deben nada a los pobres y tampoco le deben nada a la naturaleza. En el canon neoliberal, la naturaleza no crea ningún valor, ni empleo. Ambos están ahí para ser explotados por entidades corporativas. Solo los inversores (es decir, "los accionistas") y la gente en la parte superior de la pirámide son creadores de valor.

\section{¿Cuáles son los mecanismos del creciente poder ilegítimo?}

Se ejerce a través de una organización cada vez más sofisticada y profesionalizada como los grupos de presión común o lobistas. El Lobby europeo moderno está invadido por bufetes de abogados buscando un proyecto de legislación favorable y estrategias legales para sus clientes comerciales y estas empresas han demostrado ser particularmente reacias a registrarse.

El cabildeo o "relaciones públicas" de la industria creció exponencialmente después de la Segunda Guerra Mundial y ahora cuenta con expertos en la defensa de los intereses de todos los sectores industriales, incluyendo la comida chatarra, cultivos manipulados genéticamente, productos nocivos como el tabaco, sustancias químicas peligrosas o productos farmacéuticos inciertos, los mayores emisores de gases de efecto invernadero y la industria financiera. Su 
Andreu, C.R y Riccobene, E. Aproximación a un enfoque entre la globalización capitalista y la cuestión de la gobernanza. Derecho y Ciencias Sociales. Abril 2017. № 16 (Temas relativos al desarrollo regional y local) Pgs 56-72. ISNN 1852-2971. Instituto de Cultura Jurídica y Maestría en Sociología Jurídica. FCJ y S. UNLP.

misión es clara: escribir una nueva legislación; sostener o eliminar cualquier legislación que pudiera ser contraria a esos intereses.

Emplean científicos, que nunca declaren cualquier conflicto de intereses, para escribir "estudios" o artículos de divulgación dirigidas a crear dudas en la mente del público acerca de los hechos científicos incluso los más comprobados. De esta manera simulan que hay "debate", en torno a ciertas cuestiones científicas cuando en realidad no hay ninguno o solo el ficticiamente creado de la nada por los propios grupos de presión.

También utilizan técnicas de propaganda alarmistas denunciando nuevas legislaciones o regulaciones implementadas por los gobiernos, como causantes de aumentos de los costos para las empresas y en consecuencias también los precios o en su defecto causantes de aumentar el desempleo.

\section{El triunfo de la financiarización y los efectos de la crisis actual.}

Siguiendo la línea de análisis otro ejemplo concreto. Desde mediados de la década de 1990, la mayor EM estadounidense en el negocio bancario, de valores, de seguros y de contabilidad unió fuerzas empleando a 3000 personas y gastó US \$ 5 mil millones para deshacerse de todas las leyes promulgadas por el Nuevo Trato bajo la administración Roosevelt en la década de 1930-las mismas leyes que había protegido a la economía estadounidense por más de sesenta años.

A través de este empuje, del cabildeo colectivo ganaron total libertad para eliminar los activos a pérdida de sus balances y trasladarlos a bancos "sombríos" que no aparecían en ninguna parte en sus balances. Obtuvieron "la libertad" de crear y cientos de miles de millones de dólares en productos derivados tóxicos, como por ejemplo los paquetes de hipotecas de alto riesgo, sin regulación alguna. Las consecuencias, como se sabe, han sido devastadoras.

Pero la democracia ha estado ausente y no suministrado ninguna solución. Por ejemplo, desde 2007, cerca de diez millones de familias han sufrido el embargo de sus viviendas en los Estados Unidos. Tienen plena conciencia que el banco o la compañía hipotecaria tomaron su casa y los pusieron fuera en la calle-- pero la mayoría no tienen idea de cómo sucedió en realidad la crisis, o por qué el Congreso no hizo nada para evitarlo o para aliviar su situación después de sucederse los hechos. Congresistas y mujeres hicieron preparar varios proyectos de ley que podrían haber ayudado a la gente a permanecer en sus casas, pero ninguna de estas propuestas se convirtió en ley. Tampoco hubo ninguna organización colectiva para la defensa de las recientes familias sin hogar que podrían haber realizado una acción judicial. 
Andreu, C.R y Riccobene, E. Aproximación a un enfoque entre la globalización capitalista y la cuestión de la gobernanza. Derecho y Ciencias Sociales. Abril 2017. № 16 (Temas relativos al desarrollo regional y local) Pgs 56-72. ISNN 1852-2971. Instituto de Cultura Jurídica y Maestría en Sociología Jurídica. FCJ y S. UNLP.

En un área crucial como el comercio, el Observatorio Europeo de la Corporación ha demostrado que en la preparación de la Sociedad Transatlántica de Comercio e Inversiones (TTIP) entre los EE. UU y Europa se llevaron a cabo al menos 119 reuniones a puerta cerrada con las grandes empresas y sus grupos de presión, pero tan sólo unas pocas con los sindicatos y los grupos de consumidores. Cuando se anunciaron las negociaciones en febrero de 2013, ni una sola de esas reuniones había tenido lugar con los grupos de interés público, en comparación con las docenas mantenidas con los grupos de presión empresariales.

Tales noticias, como se revelan en los documentos internos obtenidos mediante el complicado recurso de acceso a la información de la UE, están en franco contraste con lo que la Comisión afirma en sus boletines informativos públicos.

Un ejemplo: "Los puntos de vista de la sociedad civil desempeñan un papel crucial en las negociaciones comerciales de la UE". Eso es cierto sólo si la "sociedad civil" se considera que se limita casi exclusivamente a los intereses empresariales.

Muchas de las normativas que se elaboran más allá de las fronteras nacionales, se refieren a la manera de permitir corporaciones de mayor alcance y libertad.

Los tratados son una importante fuente de derecho y se encuentran en el mismo orden jerárquico de las legislaciones nacionales que los receptan, aunque hay una gran cantidad de libertad de acción para los países más poderosos. Los Estados Unidos hacen caso omiso de una buena parte de la ley internacional, incluyendo las convenciones de la Oficina Internacional del Trabajo (OIT). Europa inventa y ratifica los tratados a una velocidad vertiginosa, dejando sin tiempo ni lugar para que los ciudadanos debatan o mucho menos que voten sobre ellos por referéndum

\section{¿Quién gobierna hoy en día?}

La legitimidad democrática implica la soberanía popular, también conocida como el consenso de los gobernados. Las personas que se supone que son los árbitros finales, necesitan no sólo de los representantes electos, sino también que deben tener el derecho y la capacidad de decir "no", así como "sí" a las políticas gubernamentales.

Como conclusión, este enfoque pone el eje en el peligro que entrañan las EM para la democracia no es sólo su tamaño, su enorme riqueza y los activos sino también su concentración, su capacidad de influencia y a menudo el poder de infiltración de los 
Andreu, C.R y Riccobene, E. Aproximación a un enfoque entre la globalización capitalista y la cuestión de la gobernanza. Derecho y Ciencias Sociales. Abril 2017. № 16 (Temas relativos al desarrollo regional y local) Pgs 56-72. ISNN 1852-2971. Instituto de Cultura Jurídica y Maestría en Sociología Jurídica. FCJ y S. UNLP.

gobiernos y su capacidad de actuar como una verdadera clase social internacional con el fin de defender sus intereses comerciales en contra del bien común.

\section{La Globalización: El estadio superior del Capitalismo.}

El segundo enfoque discrepa de las caracterizaciones existentes acerca del papel del estado (Robinson 2000), y se basa principalmente en la idea de lo que podríamos llamar la "transnacionalización del Estado" (ETN) partiendo desde un análisis materialista histórico de su propia transformación, puesto que desde una perspectiva Marxista "no existe un estado suspendido en el aire".

Esta visión, entiende que el Estado se encuentra en un constante proceso de cambio, y que la globalización - del sistema capitalista - lo ha subsumido en una lógica internacional que lo entiende como irrelevante - también llamadas tesis sobre "el fin del estado-nación".

La Globalización es una idea relativamente nueva en las ciencias sociales.

Se ha investigado muy bien la globalización económica. El capital ha alcanzado una nueva movilidad y ha reorganizado la producción en todo el mundo de acuerdo con todo un arsenal de políticas y de consideraciones sobre el factor costos. Esto ha traído consigo la descentralización mundial de la producción junto con la centralización de los comandos y del control de la economía global en el capital transnacional. En este proceso, los aparatos productivos nacionales han llegado a fragmentarse mientras se integran externamente en los nuevos circuitos globalizados de la acumulación.

Las relaciones de producción capitalistas están reemplazando lo que quedaba de las relaciones pre-capitalistas en el resto del mundo.

El debate sobre la globalización se ha ido centrando crecientemente sobre la relación del estado-nación con la globalización económica

a) El estado-nación (y en consecuencia el sistema intra-estatal) es visto como reteniendo su primacía, como el eje de las relaciones internacionales y del desarrollo mundial en una construcción dualista que plantea una lógica separada para una globalización económica y para un sistema político basado en un estado-nación.

b) El estado es visto, como ocurre en muchas tesis sobre "el fin del estado-nación", como si ya no fuera realmente importante.

El estado-nación es una forma históricamente específica de la organización social mundial que está en proceso de ser trascendida por la globalización capitalista. 
Andreu, C.R y Riccobene, E. Aproximación a un enfoque entre la globalización capitalista y la cuestión de la gobernanza. Derecho y Ciencias Sociales. Abril 2017. № 16 (Temas relativos al desarrollo regional y local) Pgs 56-72. ISNN 1852-2971. Instituto de Cultura Jurídica y Maestría en Sociología Jurídica. FCJ y S. UNLP.

Se discuten ambos marcos de análisis. Se avanza en la clarificación de las relaciones entre la globalización y el estado-nación, llevando la argumentación más allá de este dualismo globalnacional y desarrollando el concepto del Estado Transnacional (de aquí en adelante ETN).

a) La globalización económica tiene su contrapartida en la formación transnacional de clases y en la emergencia de un estado transnacional (ETN) que emerge para funcionar como la autoridad colectiva para la clase global gobernante.

b) El estado nacional no retiene su primacía ni ha desaparecido, sino que se ha ido transformando y ha sido absorbido en esta estructura más amplia del ETN.

c) Este ETN emergente institucionaliza una nueva relación de clases entre el capital global y el trabajo global.

d) Un aparato de ETN está emergiendo bajo la globalización desde dentro del sistema de los estados-nación

e) Consecuentemente, la globalización económica del capital no puede ser un fenómeno aislado de la transformación de las relaciones de clase y de los estados.

En la concepción weberiana, los estados son por definición instituciones vinculadas a un territorio y por ello un ETN no puede ser concebido tanto tiempo como persista el sistema estado-nación. La teoría weberiana del estado reduce el estado al aparato del estado y a sus cuadros, y con ello reifica al estado.

Los estados-nacionales son unidades jurídicas y geográficas y a veces unidades culturales. Los estados como sistemas coercitivos de autoridad son relaciones de clases y prácticas de clase congeladas y operacionalizadas mediante instituciones.

\section{Conceptualizando el Estado Transnacional. Las visiones De Weber y de Marx.}

Para Weber el Estado es un conjunto de cuadros e instituciones que ejercen autoridad. "un monopolio legítimo de la coerción", sobre un determinado territorio. En la construcción weberiana, lo económico y lo político o la dinámica "mercados y estados" son esferas separadas, y aún opuestas, que se vinculan externamente, cada una con su propia lógica independiente.

Los estados-naciones interactúan externamente con los mercados. Se observa a la globalización como entrelazad con la esfera económica, mientras la esfera política puede permanecer subyacente dentro sistema de estado-nación. 
Andreu, C.R y Riccobene, E. Aproximación a un enfoque entre la globalización capitalista y la cuestión de la gobernanza. Derecho y Ciencias Sociales. Abril 2017. № 16 (Temas relativos al desarrollo regional y local) Pgs 56-72. ISNN 1852-2971. Instituto de Cultura Jurídica y Maestría en Sociología Jurídica. FCJ y S. UNLP.

En este dualismo, la globalización económica es crecientemente influyente y reconocida, por una parte, pero es analizada como si fuera independiente de las instituciones que estructuran estas relaciones sociales, en particular, el estado-nación.

En la concepción marxista, el estado es la institucionalización de las relaciones de clases en torno a una configuración particular de la producción social. La separación de lo económico y de lo político por primera vez bajo el capitalismo acuerda a cada cual una autonomía -e implica una compleja relación que debe ser problematizada-pero también genera la ilusión de esferas externamente vinculadas.

1) Las teorías marxistas sobre la relativa autonomía del estado, aun enfatizando la subordinación "estructural" o "instrumental" del estado a las clases económicamente dominantes, no plantean un estado independiente como una esfera separada con su propia lógica (en palabras de Marx "no existe un estado suspendido en el aire").

2) No hay nada en la concepción materialista del estado que necesariamente lo circunscriba al territorio o a los estados nacionales. Los estados-nacionales son unidades jurídicas y geográficas con especificidades culturales. Los estados como sistemas coercitivos de autoridad son relaciones de clases y prácticas de clase que se operan mediante instituciones.

Como consecuencia, la globalización económica del capital no puede ser un fenómeno aislado de la transformación de las relaciones de clase y de los estados.

En este sentido el estado entendido como una relación de clases está siendo "transnacionalizado". Este ETN (Estado Transnacional) representa a aquellas instituciones y prácticas en la sociedad global que permiten avanzar la hegemonía emergente de una burguesía global y su proyecto de construir un nuevo bloque histórico capitalista global Bajo esta la globalización el estado nacional no desaparece, sino que transforma sus funciones y llega a ser un componente funcional de un ETN más amplio. Los estados nacionales no son externos al ETN sino que interactúan con éste como una parte componente. Las funciones del estado-nación están virando de la formulación de políticas nacionales a la administración de políticas formuladas a través de las instituciones internacionales.

Las organizaciones internacionales son tanto de carácter económico como político. Los foros económicos incluyen al Fondo Monetario Internacional (FMI), al Banco Mundial (BM), la Organización Mundial de Comercio (OMC), a los Bancos regionales, etc. Los foros políticos incluyen a la Comisión Trilateral, al Grupo de los 7 (G-7) (o de los 8), entre otros, así como foros formales tales como las Naciones Unidas (UN), la Organización de Cooperación 
Andreu, C.R y Riccobene, E. Aproximación a un enfoque entre la globalización capitalista y la cuestión de la gobernanza. Derecho y Ciencias Sociales. Abril 2017. № 16 (Temas relativos al desarrollo regional y local) Pgs 56-72. ISNN 1852-2971. Instituto de Cultura Jurídica y Maestría en Sociología Jurídica. FCJ y S. UNLP.

Económica para el Desarrollo (OCED), la Unión Europea (UE), la Conferencia para la Seguridad y la Cooperación en Europa (OSCE), etc.

En síntesis, el ETN trata de crear y mantener las condiciones para la valorización y la acumulación del capital a nivel de la economía global, que comprende un espacio económicopolítico mucho más amplio la suma de las economías nacionales y de las estructuras de clase nacionales y requiere una autoridad centralizada para representar al conjunto de los capitales competitivos, en donde las mayores combinaciones ya no son loa tradicionalmente llamados capitales "nacionales".

\section{El Poder de los Estados Nacionales vs el Poder del Capital Transnacional.}

Durante la fase estado-nación del capitalismo caracterizado por circuitos nacionales de producción los estados nacionales gozaron de un grado significativo de autonomía para intervenir en la fase de distribución y posibilitar que los excedentes pudieran volcarse hacia instituciones del estado-nación.

Este status era posible porque el capital, al encontrarse frente a limitaciones institucionales, territoriales y de otra naturaleza, que aparecían unidas al sistema de los estados-nacionales, enfrentaba una serie de presiones que lo forzaban a llegar a un compromiso histórico con las clases trabajadoras y populares. El resultado de la lucha de clases en este período fueron el Keynesianismo o los estados que siguieron los lineamientos del llamado "New Deal". Lo que está ocurriendo es un proceso de formación de clases transnacional, en donde la condición mediadora del estado-nación se va modificando sin desaparecer.

A medida en que las estructuras productivas nacionales se internacionalizan en sus prácticas productivas, de acuerdo a los dictámenes de los mercados internacionales van formando un entramado de clases transnacionalmente integradas. Esta nueva conformación global de clases ha entrañado una acelerada división del trabajo internacional entre una burguesía global y un proletariado globalizado. Esta división ha fijado una nueva relación global capital-trabajo, que algunos han llaman la "informalización global del trabajo" o diversas categorías afines.

La disolución del "compromiso de clases" o de "bienestar" o Keynesiano (pos segunda guerra mundial) surge del poder adquirido por el capital transnacional sobre el trabajo, que es objetivamente transnacional pero cuyo poder está limitado y cuya conciencia subjetiva está distorsionada por la continuada existencia del sistema de estado-nación. Aquí vemos cómo la permanencia del estado-nación resulta funcional a numerosos intereses de la clase capitalista transnacional. Cómo, por ejemplo, asegurar el suministro de trabajo, pues en el corazón de 
Andreu, C.R y Riccobene, E. Aproximación a un enfoque entre la globalización capitalista y la cuestión de la gobernanza. Derecho y Ciencias Sociales. Abril 2017. № 16 (Temas relativos al desarrollo regional y local) Pgs 56-72. ISNN 1852-2971. Instituto de Cultura Jurídica y Maestría en Sociología Jurídica. FCJ y S. UNLP.

todas las sociedades de clases se encuentra el control sobre el proceso de trabajo y la disposición de los productos del trabajo

También, cuando el FMI o el BM condicionan el financiamiento a la aceptación de nuevas leyes del trabajo, para hacer a los obreros "más flexibles" o retirar al estado de la política de intervención del Mercado de Trabajo estableciendo un "salario mínimo social" o arbitrando paritarias, están modificando la relación de clases.

La burguesía transnacional ejerce su poder de clase a través de una densa red de instituciones internacionales y relaciones que crecientemente se trasladan a los estados nacionales a través de la utilización de estos, como unidades jurídicas unidas a un territorio (la permanencia del sistema Inter-estatal)

\section{Del Estado de Bienestar y Desarrollista al Estados Neo-Liberal.}

El programa neo-liberal fue diseñado entre los 70 s y los 80 s por las agencias financieras internacionales y los "think tanks" de la nueva burguesía transnacional.

Este programa convocaba a la eliminación de la intervención del estado en la economía y de la regulación de los estados-nación individuales de las actividades del capital en sus territorios. Trataba de allanar las condiciones en cada país y región del mundo para garantizar la libre movilidad y la expansión del capital. Los programas de ajuste llegaron a ser los mecanismos más importantes para ajustar las economías locales a la economía global. De esta manera la reestructuración económica engendra a la reestructuración política

En los hechos, es frecuente que los presidentes de los Bancos Centrales sean designados por el FMI o el BM. El movimiento hacia la independencia del Banco Central tiene el propósito de aislar de los puestos de comando a las políticas del estado nacional, poniéndolas al margen de todo control público o de cualquier rendición de cuentas y también, para aislar a estos órganos del estado que atan a cada economía nacional con la economía global.

El poder pasa hacia las estructuras transnacionalizadas, incluyendo las redes financieras, a medida que prosigue este proceso de integración política supra-nacional se produce una pérdida de toda clase de control democrático por parte de las clases populares sobre los centros de decisión política y de distribución de recursos. Sin embargo, mientras el ETN impone sus programas de ajuste, la transnacionalización de los aparatos del estado nacional llega a ser más el resultado de estrategias adoptadas por grupos locales dominantes en el proceso de transnacionalización que por la imposición externa, como enfatiza generalmente la literatura que refleja el dualismo nacional-global. 
Andreu, C.R y Riccobene, E. Aproximación a un enfoque entre la globalización capitalista y la cuestión de la gobernanza. Derecho y Ciencias Sociales. Abril 2017. № 16 (Temas relativos al desarrollo regional y local) Pgs 56-72. ISNN 1852-2971. Instituto de Cultura Jurídica y Maestría en Sociología Jurídica. FCJ y S. UNLP.

Estos estados neo-liberales, como elementos componentes del ETN, proveen servicios esenciales al capital. Los gobiernos nacionales sirven como correas de transmisión y como filtros para la imposición de la agenda transnacional. Agréguese a esto que ellos realizan tres funciones esenciales: 1) adoptan las políticas monetarias y fiscales que aseguran la estabilidad macroeconómica; 2) proveen la infraestructura básica, necesaria para la actividad económica global (puertos y aeropuertos, redes de comunicación, sistemas educativos, etc.), y 3) proporcionan orden social, esto es, estabilidad, lo que requiere instrumentos de sostén de la coerción directa y aparatos ideológicos.

\section{Conclusiones.}

Casi todas las crisis recurrentes del capitalismo han sido mediadas por el estado-nación. Sin embargo, bajo la globalización el estado nacional es menos capaz de manejar sus crisis de tan diversa índole, así también el ETN emergente está más preparado para resolverlas, especialmente esas crisis de sobreacumulación y las de polarización social. Aun cuando el sistema financiero global pudiera ser sujeto a regulación, simplemente no existen los mecanismos para estrategias de absorción, ni el sistema provee bases para un proyecto de legitimación.

Adoptando un criterio general y no esquemático hoy nos encontramos ante un verdadero dilema para discernir en la crisis, las cuestiones de la Gobernabilidad y la Gobernanza. Los llamados gobiernos progresistas enfrentan crecientes dificultades para sostener los objetivos redistribucioncitas que son uno de los objetivos centrales de sus programas. El ET está siempre condicionando sus políticas.

\section{Defender la relevancia de Marx y la continua vitalidad del materialismo histórico no es} decir que todo lo que Marx haya dicho es todavía aplicable a las condiciones que enfrenta la humanidad en el nuevo milenio. Por el contrario, cualquier proposición de ese tipo podría llegar a ser un dogma, intelectualmente estéril y políticamente incompetente.

El argumento de Marx y de Engels de que " el proletariado de cada país debe, por supuesto resolver sus problemas con su propia burguesía", hoy está fuera de época. "Su propia burguesía" es ahora transnacional; cada burguesía "nacional" es al mismo tiempo la burguesía del proletariado de numerosos países

Las clases populares en la edad de la globalización necesitan transnacionalizar sus luchas. La movilización de la burguesía transnacional desde arriba sólo puede ser contrarrestada por una movilización transnacional desde abajo. Las clases trabajadoras y populares cuyo punto de 
Andreu, C.R y Riccobene, E. Aproximación a un enfoque entre la globalización capitalista y la cuestión de la gobernanza. Derecho y Ciencias Sociales. Abril 2017. № 16 (Temas relativos al desarrollo regional y local) Pgs 56-72. ISNN 1852-2971. Instituto de Cultura Jurídica y Maestría en Sociología Jurídica. FCJ y S. UNLP.

apoyo había sido el estado nacional, necesitan y deben transponer hacia el espacio transnacional sus manifestaciones y su capacidad para plantear demandas al sistema.

Esto significa desarrollar los mecanismos -las alianzas, las redes, las acciones directas y las organizaciones-que permitan una resistencia transnacional. Esto también significa desarrollar una ideología y política socialista transnacional que tenga en la mira al ETN como terreno a disputar. Algo así como, así como la contra Gobernanza.

\section{Bibliografía.}

Balbis, J. (2001). ONGs, Gobernancia y Desarrollo en América Latina y El Caribe. Recuperado de: http://www.unesco.org/most/dsp53_sp.htm

Camou, A.. (Estudio preliminar y compilación - 2001). Los desafíos de la Gobernabilidad. Ed.: FLACSO - IISUNAM - Plaza y Valdéz S.A. de C. V. México.

Celedón, C\& Orellana, R. (2003). Gobernancia y participación ciudadana en la reforma de salud en Chile. Recuperado de: http://www.bvsde.paho.org/bvsacd/cd29/carmenceledon.pdf

Cimadamore, A. (2004). Gobernabilidad y niveles de análisis en proceso deintegración del Mercosur. Recuperado de:

http://www.unesco.org.uy/shs/fileadmin/templates/shs/archivos/LibroDemocracia.pdf

Decoster, J.J.(2003). Gobernanza ambiental y territorial en comunidades afectadas por la explotación minera. La experiencia de las comunidades campesinas de la provincia de Espinar, Perú. Recuperado de: http://www.bvsde.paho.org/documentosdigitales/bvsde/texcom/cd050644/jdecoster.pdf

George, S. (2014). State of Corporations - The rise of illegitimate power and the threat to democracy: The State of Power. Exposing the Davos Class. Recuperado de:

https://www.tni.org/files/download/state_of_corporation_chapter.pdf

Loyo Hernández, J. C. (2002). La arquitectura de gobernanza y la gobernabilidad del sistema político venezolano. Una explicación de la estabilidad y el cambio de la democracia en Venezuela.

Recuperado

de:

http://unpan1.un.org/intradoc/groups/public/documents/CLAD/clad0043410.pdf

MINGA (2003). "El agua y la gobernanza. Contribuciones de la investigación en los Andes".

Recuperado

de:

http://www.agua.org.mx/h2o/images/stories/BibliotecaG/docs/privatizacion_del_agua/el\%20a gua\%20y\%20la\%20gobernanza.pdf

Prats, J.(2001). "Gobernabilidad democrática para el desarrollo humano. Marco conceptual y analítico". Recuperado de:

http://www.hegoa.ehu.es/dossierra/gobernanza/3-Prats2001.pdf 
Andreu, C.R y Riccobene, E. Aproximación a un enfoque entre la globalización capitalista y la cuestión de la gobernanza. Derecho y Ciencias Sociales. Abril 2017. № 16 (Temas relativos al desarrollo regional y local) Pgs 56-72. ISNN 1852-2971. Instituto de Cultura Jurídica y Maestría en Sociología Jurídica. FCJ y S. UNLP.

Robinson, W. I. (2000). Globalización capitalista y la transnacionalización del Estado. Recuperado de:

http://www.aporrea.org/actualidad/a7879.html

Román, J. \& Retolaza, I. (2001). Gobernancia local y reducción de la pobreza. Una experiencia de apoyo al diálogo nacional desde el norte Potosí. Recuperado de:

http://www.academia.edu/10685124/GOBERNANCIA_LOCAL_Y_REDUCCION_DE_LA_ POBREZA_una_experiencia_de_apoyo_al_di\%C3\%A1logo_nacional_desde_el_norte_de_Po tos\% $\mathrm{C} 3 \% \mathrm{AD}$

Santos, B. d. S. (2009). Sociología jurídica crítica. Para un nuevo sentido común en el derecho. Editorial Trotta. Madrid.

Stren, R. (2000). "Nuevos enfoques para la gobernancia urbana en América Latina". Recuperado de: www.idrc.ca/es/ev-22827-201-1-DO_TOPIC.html 